NASA Contractor Report 187166

AIAA-91-2113

\title{
Nonequilibrium in a Low Power Arcjet Nozzle
}

Dieter M. Zube

Institute für Raumfahrtsysteme

University of Stuttgart

Stuttgart, Germany

and

Roger M. Myers

Sverdrup Technology, Inc.

Lewis Research Center Group

Brook Park, Ohio

July 1991

Prepared for

Lewis Research Center

Under Contract NAS3-25266

\section{NNSN


$-\cdots=$ 


\title{
Nonequilibrium in a Low Power Arcjet Nozzle
}

\author{
Dieter M. Zube' \\ Institute für Raumfahrtsysteme \\ University of Stuttgart, Stuttgart, Germany \\ Roger M. Myers ${ }^{2}$ \\ Sverdrup Technology \\ NASA Lewis Research Center Group \\ Brook Park, Ohio 44142
}

\begin{abstract}
Emission spectroscopy measurements were made of the plasma flow inside the nozzle of a $1 \mathrm{~kW}$ class arcjet thruster. The thruster propellant was a hydrogen-nitrogen mixture used to simulate fully decomposed hydrazine. $0.25 \mathrm{~mm}$ diameter holes were drilled into the diverging section of the tungsten thruster nozzle to provide optical access to the internal flow. Atomic electron excitation, vibrational, and rotational temperatures were determined for the expanding plasma using relative line intensity techniques. The atomic excitation temperature decreased from $18,000 \mathrm{~K}$ at a location $3 \mathrm{~mm}$ downstream of the constrictor to $9,000 \mathrm{~K}$ at a location $9 \mathrm{~mm}$ from the constrictor, while the molecular vibrational and rotational temperatures decreased from $6,500 \mathrm{~K}$ to $2,500 \mathrm{~K}$ and from $8,000 \mathrm{~K}$ to $3,000 \mathrm{~K}$, respectively, between the same locations. The electron density, measured using hydrogen $\mathrm{H}_{\mathrm{k}}$ line Stark broadening, decreased from $\sim 10^{15} \mathrm{~cm}^{-3}$ to $-2 \times 10^{14} \mathrm{~cm}^{-3}$ during the expansion. The results show that the plasma is highly nonequilibrium throughout the nozzle, with most relaxation times equal or exceeding the particle residence time.
\end{abstract}

\section{Nomenclature}

C...............constant for calculating vibrational relaxation

c............specific heat capacity, $\mathrm{J} / \mathrm{kg} / \mathrm{K}$

E..............excited state energy, $J$

$\mathrm{E}_{\mathrm{H}} \ldots \ldots . . . . . . .$. hydrogen ionization energy, $13.6 \mathrm{eV}$

f.............oscillator strength

g.............statistical weight

G.............vibrational excitation energy level, J

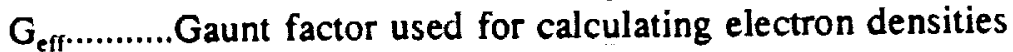

H..............neutral atomic hydrogen

I...............intensities integrated over the complete spectral line or band

\footnotetext{
'Graduate Student, Institute fur Raumfahrtsysteme, University of Stuttgart, Germany
}

${ }^{2}$ Propulsion Engineer, Member AIAA 


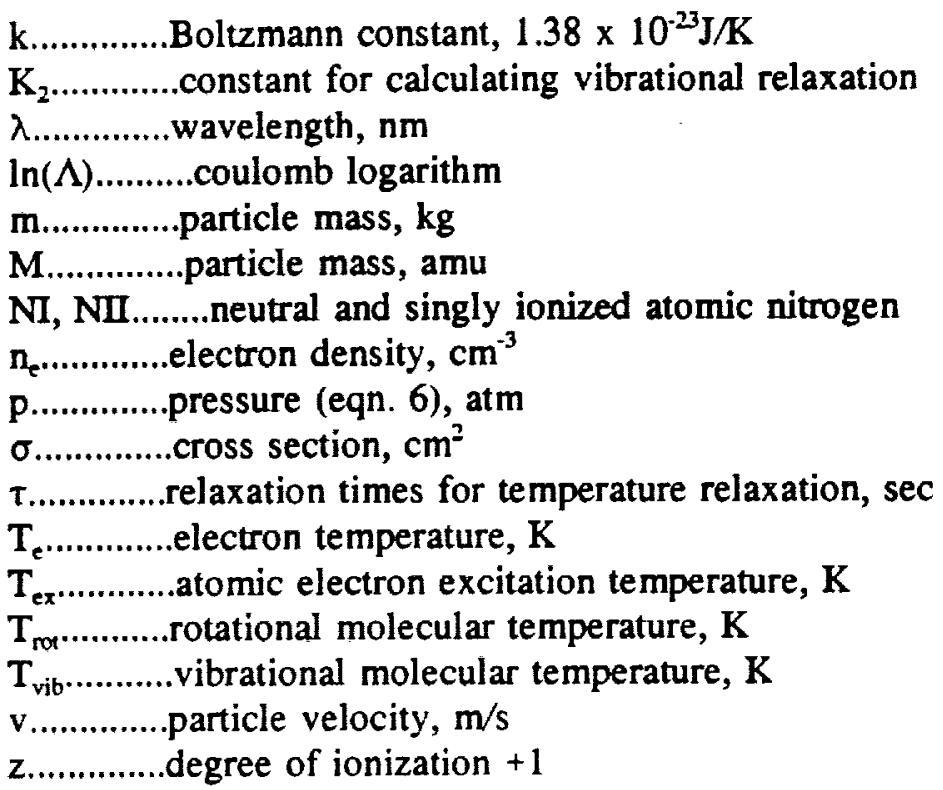

\section{Introduction}

Selection of $1 \mathrm{~kW}$ class arcjet thrusters for station keeping application on the Telstar IV series satellites has dramatically increased interest in arcjet technology. The ability to achieve specific impulses from 450 to 550 seconds with storable propellants, and the system simplicity makes arcjets attractive for application to geosynchronous satellite station keeping. Furthermore, modern satellite power busses have the capability to provide the required power/duty cycle combination for these thrusters. While arcjets have been accepted by the satellite community for geosynchronous stationkeeping, there is considerable room for improved thruster performance. Current arcjets convert only $25-35 \%$ of the input power into thrust power, with the dominant losses lying in unrecovered power deposited into the propellant. This paper describes an effort to empirically study the nozzle plasma in the expectation that a detailed understanding of the dominant physics will permit improvements of the arcjet.

In a typical arcjet, shown in Fig. 1, an arc is struck between the central, conical-tipped cathode and the coaxial, nozzle shaped anode. Propellant, injected with high swirl near the cathode tip, passes through the constrictor region (throat) and is ohmicaly heated by the arc. Curran ${ }^{1}$, using an axially segmented arcjet anode, showed that the anode current attachment extends all the way down the length of the nozzle. This result demonstrated that energy is transferred to the gas throughout the entire flow passage, including subsonic, transition, and supersonic flow regimes. The energy transfer to the gas is thought to result predominantly from electron-ion or electron-neutral collisions as electrons are the dominant current carriers.

These collisions distribute the arc energy to several sinks, including random thermal 
energy of the propellant, dissociation, ionization, and excitation of bound rotational, vibrational and electronic states. Energy deposited into these modes which is not converted to directed kinetic energy of the exhaust constitutes the major loss mechanism for arcjet thrusters. While an analytical understanding of these processes is clearly required, the complexity of the flow field and plasma physics presently precludes an ab initio approach. To provide improved insights into the internal arcjet flows, efforts were initiated to develop the diagnostic techniques required to directly measure several of the principal plasma parameters.

Most studies of arcjet plasmas have concentrated on the thruster plume. Studies utilizing Langmuir probes ${ }^{2,3}$ and emission spectroscopy ${ }^{4}$ have established electron density and temperature profiles and identified the dominant species in the plume downstream of the exit plane. Janson, et.al $^{5}$ found differences between the plume spectrum of an arcjet tested with ammonia and one tested with a nitrogen-hydrogen mixture chosen to simulate ammonia. While this indicates that the mixture used in this study to simulate hydrazine may not exactly represent a hydrazine arcjet, it should be noted that in a flight-type system, hydrazine is decomposed in a catalyst bed before being injected into the arcjet, and performance comparisons ${ }^{6}$ indicate only small differences between simulated and actual hydrazine propellants. The only previous study of the internal arcjet plasma was performed on a low power helium arcjet with a $2 \mathrm{~mm}$ diameter quartz constrictor ${ }^{7}$. However, due to the temperature restrictions of the quartz and the impact of the window on the energy transfer processes in the constrictor, it would be unrealistic to relate their results to flight-type arcjet thrusters.

This paper presents the results of an effort to non-intrusively measure the plasma properties in an arcjet thruster similar to those planned for flight application. Following a description of the experimental apparatus and thruster operating characteristics, the measurements and their analysis are presented, including identification of the plasma constituents, atomic and molecular temperatures, and the electron density. The results are then used to estimate various plasma relaxation rates. Finally the implications of the results for energy transfer processes and plasma models are discussed.

\section{Experimental Apparatus}

The thruster used in this experiment was a $1 \mathrm{~kW}$ class laboratory model device developed at the NASA Lewis Research Center ${ }^{8}$. The thruster was similar to those planned for application on geosynchronous communications satellites. The arcjet, shown in Fig. 1, consisted of a conical-tipped, $2 \%$ thoriated tungsten cathode, a $0.064 \mathrm{~cm}$ diameter by $0.064 \mathrm{~cm}$ length constrictor, and a conical nozzle/anode with an expansion angle of $20^{\circ}$ and an area ratio of $225: 1$. Additional testing was performed with a nozzle expanding to an area ratio of 400:1 (same expansion angle). The anode material was $2 \%$ thoriated tungsten and all insulators were made of boron nitride.

The thruster was operated in a $0.64 \mathrm{~m}$ diameter by $0.64 \mathrm{~m}$ length vacuum chamber 
evacuated using a mechanical roughing pump. The propellant flow consisted of a mixture of 59 $\mathrm{mg} / \mathrm{s}$ hydrogen and $41.6 \mathrm{mg} / \mathrm{s}$ nitrogen (to simulate fully decomposed hydrazine) and was kept constant during all experiments. With this flow rate the pump maintained a back pressure of about $120 \mathrm{~Pa}$. This back pressure, while affecting the plume, changed the thruster performance (thrust and voltage) by less than $5 \%^{6}$. The power supply ${ }^{9}$ delivered a stable current that was varied between 9 and $12 \mathrm{~A}$ for the experiments. The thruster performance was measured on a thrust balance in a separate separate facility with higher pumping speed described in Ref. 1 .

Two optical diagnostic techniques, described in Ref. 10, were developed to measure the emission spectra of the internal nozzle plasma. The more successful technique consisted of drilling $0.25 \mathrm{~mm}$ diameter holes radially into the nozzle wall at desired axial and radial positions to gain optical access to the plasma inside the nozzle. As described in the next section, these

holes had no measurable impact on the arcjet performance and there was no evidence of preferential current attachment around the holes. The hole locations, shown in Fig. 2, were chosen to provide measurements at three area ratios in the 225:1 nozzle and to obtain coarse radial profiles in both the $225: 1$ and $400: 1$ nozzles. The radial profiles were obtained at only one axial location with the 225:1 nozzle and two axial locations in the 400:1 nozzle. While a simple Abel inversion could be applied to the radial measurements, the resolution was limited to $1 / 4$ the nozzle radius by the small nozzle size.

The optics required to image the individual holes onto the spectrometer entrance slit are shown in Fig. 3. Two lenses were required to satisfy the spatial and magnification requirements and an iris aperture was used to eliminate stray light emitted from the glowing nozzle wall. In order to select an individual hole, the thruster was moved vertically inside the vacuum chamber on a stepper motor driven rail table until the desired hole was at the image location of the light path.

The $0.5 \mathrm{~m}$ Czerny-Turner spectrometer was equipped with a 2400 grooves/mm grating and an intensified 1025 pixel diode array detector to measure line intensities. The spectral resolution of the instrumentation was 0.016 to $0.019 \mathrm{~nm}$ per detector pixel, depending on the observed wavelength. Spectra were observed in real time to permit adjustment of the diode array integration time before storing them for later analyses.

\section{Experimental Results}

The current - voltage characteristic of the arcjet was obtained at the beginning of each measurement series to ensure the thruster was operating normally. Thrust measurements showed that the presence of the $0.25 \mathrm{~mm}$ diameter holes in the nozzle wall had no measurable effect ( $\leq$ $2 \%$ ) on the thruster performance. This was verified by testing the thruster with the nozzle wall holes both sealed and open. These data, obtained with the 225:1 nozzle with axial holes, are summarized in Table 1. Excellent agreement was obtained with the lifetest results reported by Curran ${ }^{8}$.

In addition to the optical system complexity and small nozzle size, the measurements were 
hindered by light reflection from the nozzle wall. This issue is distinct from that of the glowing nozzle wall contributing continuum radiation, and is due to plasma luminosity reflecting of the inner nozzle surface into the holes through which the measurements were made. This precluded a precise determination of the region where the light originated. The magnitude and origin of this light was determined by the nozzle geometry and surface reflectance. To establish the importance of this effect a small LED was slowly inserted up into the nozzle with the axial holes (geometry A in Fig. 2) and the light intensity emitting from the holes was measured as a function of the LED location. For each hole there were two axial positions at which the LED provided a measurable signal: the primary location when the LED was directly beneath the hole and the secondary corresponding to the location that caused direct reflection into the hole. The secondary peak was brightest for the hole closest to the exit plane, but never exceeded $30 \%$ of the intensity of the direct illumination. It is important to note that this experiment utilized a constant intensity source, whereas the plasma luminosity decreased rapidly in the downstream direction. While this intensity reduction mitigated the importance of reflected light, it was not possible to exactly quantify the impact of this problem.

Whenever possible the quantitative results were obtained from spectra separated by less than $40 \mathrm{~nm}$ to avoid the difficulties associated with intensity calibrations. For all measurements of steady-state conditions the thruster was turned on and allowed to stabilize for 15-20 minutes before a final alignment check was made to account for thermal expansion of the nozzle and arcjet components. Measurements were performed at least three times to ensure repeatability. The uncertainties of the results were calculated by propagating the errors of the individual parameters using standard algorithms ${ }^{11}$.

\section{Plasma Species}

The plasma species identified from a spectrum recorded between 320 and $750 \mathrm{~nm}$ are listed in Table 2. Only species for which several lines were identified are reported. Observed wavelenghts were compared with tabulations in Ref. 12,13 and 14. In addition to the molecular and atomic propellant species, tungsten impurity, $\mathrm{NH}$, and $\mathrm{NH}_{2}$ lines were observed. The high NH intensities observed at all axial positions indicates that recombination was taking place throughout the nozzle. Although the $\mathrm{NH}_{2}$ and tungsten spectral lines were visible in most experiments, their intensities were too low to use them for more detailed investigations.

\section{Plasma Properties}

The spectral data were used to determine several plasma temperatures and the electron density. The temperatures included the atomic excitation temperature for NI, NII, and $\mathrm{H}$, and molecular vibrational and rotational temperatures for $\mathrm{N}_{2}$. All temperatures were calculated assuming that the populations of the observed excited states followed a Boltzmann distribution at the local temperature. The validity of this assumption was checked a posteriori.

\section{Atomic Excitation and Free Electron Temperatures}

The atomic excitation temperature $T_{e x}$, was determined from emission line intensity ratios. This temperature can be calculated from two different lines (denoted ${ }_{1}$ and 2 ) of the same 
species $^{15}$ :

$$
T_{e x}=\frac{E_{1}-E_{2}}{k \ln \left[I_{2} \lambda_{2}^{3} g_{1} f_{1} / I_{1} \lambda_{1}^{3} g_{2} f_{2}\right]}
$$

The spectral lines used for this measurement are listed in Table 3, along with their oscillator strengths and the degeneracies of the upper excited states. A relative calibration was needed for the hydrogen measurements due to the wide wavelength separation of the observed transitions.

The axial excitation temperature distributions for $\mathrm{NI}, \mathrm{NI}$ and $\mathrm{H}$ for thruster operation at currents of 9 and 12 amps with the 225:1 nozzle are shown in Figures 4a - c. While the absolute uncertainties are large, most of the error was due to the oscillator strengths, which does not affect the validity of the observed trends. The excitation temperatures for the three species were similar, dropping from $\sim 18,000 \mathrm{~K}$ at an area ratio of $1: 10$ to $\sim 10,000 \mathrm{~K}$ at an area ratio of 1:125. The excitation temperature increased slightly with arc current.

Radial electron excitation temperature profile measurements were hindered by the rapid decrease in line intensities away from the nozzle axis. For this reason, only the hydrogen excitation temperature could be measured. The measurement was made at four radial positions in both the 225:1 and 400:1 area ratio nozzles. The radial holes divided the nozzle section into four shells with an equal thickness of one fourth of the radius. The Abel inversion technique used assumed a uniform intensity in each of the individual ring shells, and the intensity in a radial ring was calculated from the geometric size of the observed shell portion ${ }^{16}$. This simple technique was used because the small nozzle dimensions precluded measurements at a large number of radial locations. The measured spectra were inverted and the plasma properties were determined from the inverted intensities. As shown in Fig. 5a and $b$ the hydrogen excitation temperature did not vary within the inner $87 \%$ of the nozzle radius for either nozzle.

Background radiation from the glowing nozzle precluded direct measurement of the free electron temperature from continuum radiation. However, several arguments can be introduced to show that the electron temperature was near the atomic excitation temperature. First, there is the close agreement of excitation measurements for NI, NII, and H. Given the different crosssections, radiative rates, and densities, it seems unlikely this agreement would occur unless the upper excited state populations were controlled by the same mechanisms of electronic collisional excitation and radiative decay. Second, the energy levels used for the measurements were close to the ionization potentials for the atoms. For example, for NI the measured states were less than $0.6 \mathrm{eV}$ from the continuum. Third, the electron densities measured using Stark broadening were close to the threshold established by Griem ${ }^{15}$ for partial local thermal equilibrium, a condition for which $T_{e x}=T_{e}$. The latter result is further discussed in section IV.

\section{Molecular Vibration Temperature}

The nitrogen vibrational temperature was determined from the intensity ratio of two transitions. According to Herzberg ${ }^{12}$ it can be calculated from two molecular bands (denoted ${ }_{1}$ 
and ${ }_{2}$ ):

$$
T_{v i b}=\frac{G_{1}-G_{2}}{k \ln \left[I_{2} \lambda_{2}^{4} f_{1} / I_{1} \lambda_{1}^{4} f_{2}\right]}
$$

Only two spectral bands, listed in Table 4 with the appropriate constants, were sufficiently intense and free from overlapping lines or bands to be used for the vibrational temperature determination. While the oscillator strengths for atomic transitions are well known for most species $^{13}$, only a few have been measured for molecular transitions and the uncertainty is larger. Thus, the absolute uncertainty of the vibrational temperature determination is rather large $( \pm 25$ $\%)$, though trends are accurate to within experimental error ( $\pm 10 \%)$.

Typical vibrational temperature measurements for the $225: 1$ nozzle at 9 and $12 \mathrm{~A}$ are shown in Fig. 6, where it is seen that the temperature decreased from $\sim 6500 \mathrm{~K}$ near the constrictor to $\sim 2500 \mathrm{~K}$ at an area ratio of $126: 1$. While there was a slight dependence on arc current at the upstream end of the nozzle, this disappeared toward the exit plane. Radial profiles could not be measured due to the rapid decrease in spectral intensity at higher radii.

\section{Rotational Temperature}

The intensity ratio method could not be used to determine rotational temperatures because the rotational lines were too close together and overlapped, precluding the separation of individual lines within one band. To overcome this problem, the theoretical intensity distribut on for a band was calculated with an assumed rotational temperature and compared to the measured spectrum. The rotational temperature was found iteratively by varying the temperature of the theoretical distribution, a method used by several other authors ${ }^{4,17,18}$. An examination of the observed spectrum led to selection of the $N_{2} C^{3} \Pi_{u}-B^{3} \Pi_{q}$ transition band at $375.5 \mathrm{~nm}$. The equations governing the distributions the of $P, Q$ and $R$ rotational branches were taken from Herzberg ${ }^{12}$, and the appropriate wavelengths were obtained from Pearse and Gaydon ${ }^{14}$. Fifty transitions for each of the three branches were included for each vibrational band. A simple inverted parabola line shape was used for each transition to reduce computional time. This assumption had little effect where the lines were slightly separated, but introduced substantial errors near the band heads where the lines nearly completely overlap.

Figure 7 shows measured and calculated molecular bands for $\mathrm{N}_{2}$. It is clear that the distribution was well predicted away from the band head at $399.8 \mathrm{~nm}$, but that the intensity of the band head itself was underpredicted. The agreement between the measured and calculated spectra, the latter based on a Boltzmann distribution, indicated that the rotational levels were not far from an equilibrium state. The discrepancy at the band head may have been due either to the assumed line profile or an overpopulation of the lower states. Figure 8 shows the rotational temperatures for the 225:1 nozzle at currents of 9 and $12 \mathrm{~A}$ determined with this technique. The rotational temperature was found to be higher than the vibrational temperature, and the rotational temperature decreased more rapidly than the vibrational temperature. Note that for $T_{\text {ror }}$ the increase in temperature with current level was evident throughout the nozzle.

The temporal behavior of the three plasma temperatures was measured in an attempt to 
establish the importance of wall heat transfer to the plasma characteristics. Shown in Fig. 9 are the mean results from 100 spectra recorded every 0.5 to 3 seconds during the start-up phase of an arcjet test. The recording of the spectra was started before thruster ignition to study the start up phase, A curve of the form $T=T_{0}(1-\exp (-t / \tau))$ was used to calculate the desired time constant, $\tau$, for each plasma temperature. The time constants for the various plasma properties, listed in Table 5, were of the same order for all the plasma temperatures. The time constants varied with axial position in the nozzle, ranging from $\sim 5$ second near the constrictor, to $\sim 8.5$ seconds near the exit plane. The time constant for the nozzle temperature was approximately 130 seconds, and the thrust time constant was -2 seconds. Given that the current and voltage rise times were $<\sim 2$ seconds, this result implies that wall heat transfer played only a small role in plasma energy transfer for these operating conditions. It appears, however, that the observed equilibration times result from either thermal or mechanical relaxation of the arcjet components, since the rise times are much longer than acoustic or plasma relaxation rates.

\section{Electron Density}

The electron number density was determined from the Stark width of the hydrogen $\mathrm{H}_{4 \mathrm{l}}$ line $(486.1 \mathrm{~nm})^{19}$. After the full width at half maximum (FWHM) for the line had been determined using a Lorentzian fit to the observed profile, the Doppler and Stark broadening contributions were deconvoluted using the results presented in Ref. 19. This process required knowledge of the hydrogen kinetic temperature, which was set equal to the electron temperature based on relaxation rate calculations presented in Section IV.

Typical results, shown in Fig.10, show that the density decreased from $-10^{15} \mathrm{~cm}^{3}$ to $-2 \times 10^{14} \mathrm{~cm}^{-3}$ from axial locations at area ratios of $10: 1$ to $126: 1$. While it is clear that the upstream electron density increased with current level, the downstream density was not sensitive to the arc current. This may be a reflection of the nozzle current distribution.

The radial electron density distribution was measured at an area ratio of $126: 1$ for both the 225:1 and 400:1 area ratio nozzles. Measurements in the downstream holes for the longer nozzle were precluded by the low electron density and low spectrometer resolution. Line profiles were obtained at each radial station and the resulting profiles Abel inverted to obtain the FWHM as a function of radius. The resulting electron density profiles, shown in Fig. 11, are flat. This result, in combination with the excitation temperature measurements, shows that there was a wide central region with relatively uniform properties which was bounded by steep gradients near the wall. The increased density observed with the longer nozzle may be due to the presence of substantial current downstream of the measurement point. In other words, the arc current may extend over most of anode length anode for both the 400:1 and 225:1 nozzles; since these measurements were made at an area ratio of $126: 1$ with for both of the nozzles, a larger fraction of the current may extend beyond the measurement point with the longer nozzle than with the shorter one.

It is interesting that these measurements correlate well with measurements made in the thruster plume. The plume measurements shown in Fig. 12 were made using $\mathrm{H}_{4}$ Stark broadening (close to the nozzle) and Langmuir probes. 


\section{Discussion}

The large difference between the atomic excitation, vibrational and rotational temperatures clearly shows the plasma to be in a nonequilibrium state throughout the nozzle. The excitation temperature was more than twice as large as either molecular temperature throughout the expansion, and the rotational temperature was higner than the vibrational temperature. Three justifications were presented for equating the excitation temperature to the free electron temperature. First, $T_{e x}$ was the same for the three species for which it was measured. Second, the excited states used in the measurement were energetically close to the continuum. Third, the states observed and the electron densities satisfied the partial local thermal equilibrium (PLTE) criterion developed by $\mathrm{Griem}^{15}$, and modified by $\mathrm{Hey}^{20}$ for nonhydrogenic systems. This criterion is written as a lower electron density bound for which the excited state population is controlled by the free electron temperature:

$$
n_{\bullet} 2 \frac{2.55 \times 10^{17}}{G_{\text {eff }}}\left[\frac{\Delta E_{1-2}}{E_{H}}\right]^{3} \sqrt{\frac{k T_{e}}{E_{H}}}
$$

where the effective Gaunt factors, $G_{\text {eff }}$, were obtained from van Regemorter ${ }^{21}$. This criterion establishes a lower bound of $1 \times 10^{15} \mathrm{~cm}^{-3}$ for the $18,000 \mathrm{~K}$ temperature near the constrictor and $8 \times 10^{15} \mathrm{~cm}^{-3}$ for the $7000 \mathrm{~K}$ temperature near the exit plane. Thus, based on this PLTE criterion, equating the excitation temperature to the free electron temperature is acceptable near the constrictor but unjustified near the exit plane. However, Skorupski and Suckewer ${ }^{2}$, have shown that heavy particle elastic collisions can dramatically relieve the electron density requirements for PLTE. This coupled with the first two arguments above indicate that setting $T_{e x}=T_{e}$ was a reasonable approximation.

Several plasma relaxation rates were evaluated to establish which processes played a dominant role in the plasma expansion. These should be compared with the average particle residence time in the nozzle, which was estimated to be $\sim 5 \times 10^{-6}$ seconds by dividing the nozzle length by one-half the exhaust velocity. The latter was estimated from the measured specific impulses. The plasma relaxation times, summarized in Table 6 , were calculated using the temperature and density measurements presented above and relations from Vincenti and Kruger ${ }^{23}$ and Venugopalan ${ }^{24}$. For example, the energy equilibration times between the observed plasma species were used to establish the atomic hydrogen kinetic temperature. This relaxation time, given $b^{24}$

$$
\tau_{1-2}=1.3 \times 10^{-5} \frac{\left(M_{1}+M_{2}\right)^{2}}{n_{2} M_{1} M_{2}^{0.5}\left\langle\sigma_{1-2}\left(T_{2}\right)>T_{2}\right.}
$$

where the subscripts refer to the species in question, was used to compare the $\mathrm{H}$ atom - $\mathrm{N}_{2}$ relaxation and the $\mathrm{H}$ atom - electron relaxation. In these estimates the $\mathrm{N}_{2}$ kinetic temperature was assumed to be equal to the measured rotational temperature and the $\mathrm{N}_{2}$ density was set to $\sim 10^{16} \mathrm{~cm}^{-3}$ based on the propellant flow rate, nozzle area and exhaust velocity. The momentum transfer cross-section for $\mathrm{H}-\mathrm{N}_{2}$ collisions is not known, so it was estimated from the geometric particle radii ${ }^{25}$. The cross - section for electron - hydrogen collisions was obtained from Ref 26. The results, a relaxation time of $10^{-6}$ seconds for electron - hydrogen collisions, and $2 \times 10^{-7}$ 
seconds for $\mathrm{N}_{2}-\mathrm{H}$ were inconclusive. However, when the relaxation times were calculated for electron - proton and proton - atomic hydrogen collisions the results were more significant. The large Coulomb cross - section for the electron - proton interaction gives a relaxation time relation of 24

$$
\tau_{\bullet Q}^{0-p}=2.5 \times 10^{2} \frac{T_{e}^{3 / 2}}{n_{p} \ln (\Lambda)}
$$

which, for the measured conditions, yields a relaxation time of $10^{-8}$ seconds. Equation 4 yields a time of $10^{-9}$ seconds for the $\mathrm{H}-\mathrm{P}$ relaxation. Thus, the two-step process, consisting of an electron - proton collision followed by a proton - neutral hydrogen collision, is two orders of magnitude faster than the single step nitrogen molecule - hydrogen atom collision process. This led to the use of the electron excitation temperature as an estimate for the kinetic hydrogen temperature when the Doppler broadening was calculated in Section III. Similar two-step processes were investigated to check additional processes (electron - NII, NII $-\mathrm{H}$ and $\mathrm{N}_{2}-\mathrm{N}$, $\mathrm{N}-\mathrm{H}$ ), but they were found to be slower than the electron $-\mathrm{H}^{+}, \mathrm{H}^{+}-\mathrm{H}$ process described above. This is a result of the large mass difference between hydrogen atoms and nitrogen molecules $(1: 28)$ that slows this process and the fast relaxation between electrons and protons due to the large Coulomb cross-section.

While the measured rotational and vibrational temperatures were the same near the exit plane, the rotational temperature appeared to be slightly higher close to constrictor (Fig. 8). The observed difference in the behavior of the two temperatures during the expansion may result from the different relaxation times for the two processes. The rotational relaxation is somewhat slower than the translational relaxation ${ }^{23}$. With equation 4 the translational relaxation was calculated to be $10^{-7} \mathrm{~s}$, so the rotational relaxation should have a time constant of $10^{-6}$ to $10^{-7} \mathrm{~s}$. The vibrational relaxation was calculated from $^{23}$

$$
\tau=C \frac{e^{\left(K_{2} / T\right)^{1 / 3}}}{p}-
$$

where the temperature $T$ is in Kelvin and the pressure $p$ in atm. The constants $C$ and $K_{2}$ depend on the gas, for nitrogen $\mathrm{K}_{2}=1.91 \times 10^{6} \mathrm{~K}$ and $\mathrm{C}=7.12 \times 10^{-9} \mathrm{~s}$ atm. The shortest possible time constant results from using the propellant feed pressure in eqn. 6 , which results in a time constant of $10^{-6}$ seconds. Of course, during the expansion this value will increase by over three orders-of magnitude, so that the vibrational relaxation times are the longest time constants for the nozzle plasma. The difference in the time constants for rotation and vibration would explain the difference in the slope for these two temperatures.

\section{Conclusion}

The spectroscopic analysis of the light emitted from the plasma inside the nozzle of a 1 $\mathrm{kW}$ class arcjet thruster operated with a 2:1 hydrogen: nitrogen mixture showed the expected atomic and molecular nitrogen and hydrogen spectral lines. In addition, considerable NH and small traces of $\mathrm{NH}_{2}$, and tungsten, eroded from the electrodes, were found. Measurements of 
excitation, vibrational, and rotational temperatures showed the plasma to be in a nonequilibrium state throughout the nozzle. It appears that the upper atomic excited states can be described using a PLTE model, though this should be investigated carefully for the plasma near the exit plane. A collisional - radiative model, allowing for a minimum of two fluid temperatures, will be needed to accurately model the arcjet plasma expansion. The atomic excitation temperature was found to drop from $18,000 \mathrm{~K}$ to $9,000 \mathrm{~K}$ during the expansion, and the molecular temperatures were found to be lower than the atomic, ranging from $6,500 \mathrm{~K}$ to $3,000 \mathrm{~K}$ for the vibrational and $8,000 \mathrm{~K}$ to $3,000 \mathrm{~K}$ for the rotational temperature, respectively. The electron density dropped from $-1 \times 10^{15} \mathrm{~cm}$ near the constrictor to $2 \times 10^{14} \mathrm{~cm}^{-3}$ near the exit, and was sensitive to the arc current only near the constrictor. Radial profiles of the excitation temperature and electron density showed that both were flat over the observed $87 \%$ of the nozzle radius. This showed the presence of a broad central region with low gradients, surrounded by high gradients at the walls. The relaxation times calculated for the plasma conditions qualitatively explain the different temperature trends, and show that the free electron temperature should be close to the atomic hydrogen temperature. The latter could only be conclusively demonstrated using a two collision process, involving a hydrogen ion - electron Coulomb collision followed by a hydrogen ion - hydrogen neutral collision.

Acknowledgements

The authors would like to thank George Jacynicz, Fred Jent, Jeff MacBeth and Elmer Petelka for their invaluable assistance on this project. We are also grateful to Scharlene Schmidt for her help in preparing the manuscript. This work was supported in part with a scholarship from the German Studienstiftüng des Deutschen Volkes.

\section{References}

1. Curran, F.M., Manzella, D.H. and Pencil, E.J.,"Performance Characterization of a Segmented Anode Arcjet Thruster," AlAA Paper 90-2582, July, 1990.

2. Carney, L.M., "An Experimental Investigation of an Arcjet Exhaust Using Langmuir Probes," NASA TM 102346, 1988.

3. Sankovic, J., "Investigations of the Arcjet Plume Near Field Using Electrostatic Probes," presented at the JANNAF Propulsion Meeting, Anaheim, CA, October 1990, see also NASA TM 103638.

4. Manzella, D.H., Curran, F.M., Myers, R.M. and Zube. D.M.,"Preliminary Plume Characteristics of an Arcjet Thruster," AIAA Paper 90-2645. July, 1990.

5. Janson, S., et al.," Arcjet Plume Characterization, Part II: Optical Diagnostic Analysis," AIAA Paper 90-2643, July 1990.

6. Curran, F.M., Private Communication, NASA Lewis Research Center, Cleveland, $O H$, May 1991.

7. Ishii, M and Kuriki, K., "Optical and Analytical Studies of Arc Column in DC Arcjet", AIAA Paper 87-1086, May 1987.

8. Curran, F.M. and Haag, T.W.. "An Extended Life and Performance Test of a Low Power Arcjet," AIAA Paper 88-3106, July. 1988. see also NASA TM 100942. 
9. Gruber, R.P., "Power Electronics for an 1-kW Arcjet Thruster," AIAA Paper 86-1507, July 1986, see also NASA TM 87340.

10. Zube, D.M. and Myers, R.M., "Techniques for Spectroscopic Measurements in an Arcjet Nozzle," accepted for publication in J. Propulsion and Power, 1990.

11. Bevington, P., "Data Reduction and Error Analysis for the Physical Sciences," McGraw Hill, 1969.

12. Herzberg, G., "Molecular Spectra and Molecular Structure, I. Spectra of Diatomic Molecules, "D. van Nostrand Comp., 1959.

13. Reader, J., Corliss, C.H., Wiese, W. L. and Martin,G.A., "Wavelengths and Transition Probabilities for Atoms and Atomic Ions, Part I: Wavelength, Part II: Transition Probabilities," National Bureau of Standards, 1980.

14. Pearse, R. and Gaydon, A., "The Identification of Molecular Spectra", 2nd ed., John Wiley \& Sons, New York, 1950.

15. Griem, H.R., "Plasma Spectroscopy," 1.ed, McGraw Hill, 1964.

16. Lochte-Holtgreven, W., "Plasma Diagnostics," North Holland Publishing Comp., 1968.

17. Piper, L.G. et al., "Experimental Determination of Einstein Coefficients for the $\mathrm{N}_{2}$ (B-A) Transition," J. Chem. Phys., Vol.90 No.10, May 1989.

18. Beylich, A.E., "Experimental Investigation of Carbon Dioxide Jet Plumes," The Physics of Fluids, Vol.14, No.5, p.898, May 1971

19. Huddlestone, R.H. and Leonard, S.L., "Plasma Diagnostic Techniques," I.ed, Academic Press 1965.

20. Hey, J.D., "Criteria for Local Thermal Equilibrium in Non-Hydrogenic Plasmas," Journal f. Spectroscopic Radiative Transfer, Vol.16, 1976.

21. Regemorter, H.v., "Rate of Collisional Excitation in Stellar Atmospheres," Astrophysical Journal 136, p.906, 1962.

22. Skorupski, A. and Suckewer, S., "Nonthermal equilibrium parameters of weakly ionized plasma," J. Phys. B: Atom, Molec. Phys., Vol. 7, No. 11, Nov. 1974 pp 1401-1410.

23. Vincenti, W.G. and Kruger, C.H., "Introduction to Physical Gas Dynamics," Robert E. Krieger Publishing Co., New York, 1967.

24. Venugopalan, M., "Reactions under Plasma Conditions," Wiley Interscience, 1965.

25. Weast, R.C, ed., "CRC Handbook of Chemistry and Physics," 53rd ed, CRC Press, 1972.

26. Mitchner, M. and Kruger, C., "Partially Ionized Plasmas," Wiley-Interscience Publ., 1973. 


\begin{tabular}{|c|c|c|c|}
\hline \multicolumn{4}{|c|}{ Current Settings, A } \\
\hline Parameter & $9 \mathrm{~A}$ & $10 \mathrm{~A}$ & $11 \mathrm{~A}$ \\
\hline \multicolumn{4}{|c|}{ specific power $(\mathrm{kJ} / \mathrm{kg})$} \\
\hline sealed holes & 21510 & 23360 & 25160 \\
\hline open holes & 21310 & 23260 & 25080 \\
\hline \multicolumn{4}{|l|}{ thrust (mN) } \\
\hline sealed holes & 206 & 213 & 220 \\
\hline open holes & 204 & 212 & 219 \\
\hline \multicolumn{4}{|c|}{ specific impulse (s) } \\
\hline sealed holes & 422 & 436 & 451 \\
\hline open holes & 419 & 435 & 449 \\
\hline \multicolumn{4}{|c|}{ thrust efficiency $(\%)$} \\
\hline sealed holes & 39.8 & 39.3 & 38.9 \\
\hline open holes & 39.2 & 39.1 & 38.7 \\
\hline
\end{tabular}

Table 1: Thruster performance with 225:1 expansion ratio nozzle with open and sealed holes

\begin{tabular}{|c|}
\hline Identified Wavelengths, nm \\
\hline 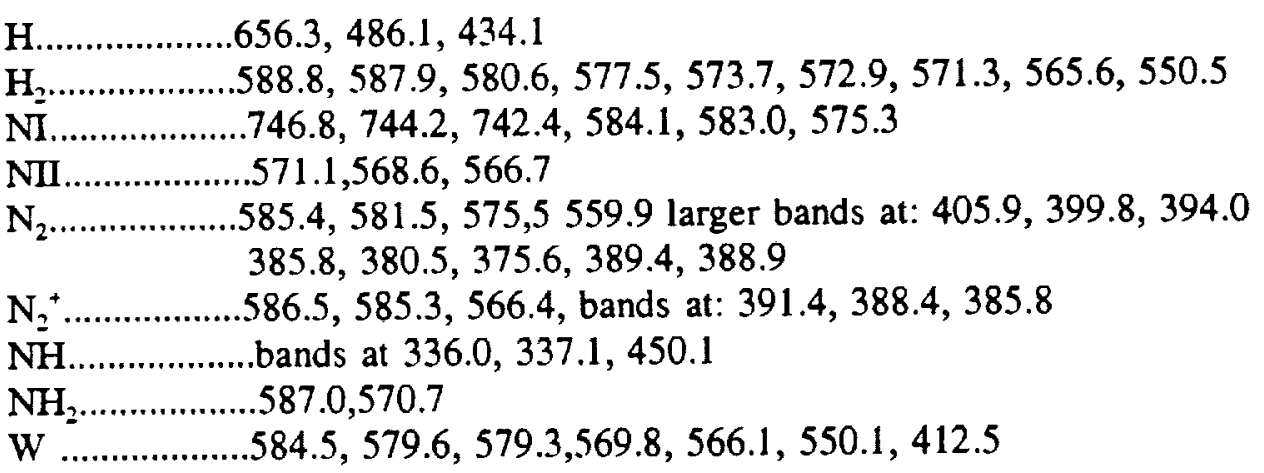 \\
\hline
\end{tabular}

Table 2: Species Identified within the Arcjet Nozzle 


\begin{tabular}{llll}
\hline \hline Species & $\lambda_{\mathrm{ik}}(\mathrm{nm})$ & $\mathrm{f}_{\mathrm{ik}}$ & $\mathrm{g}_{\mathrm{i}}$ \\
\hline \hline \multirow{3}{*}{ NI } & & & \\
& 583.0 & 0.00328 & 6 \\
& 583.4 & 0.00390 & 2 \\
NII & 585.0 & 0.00152 & 2 \\
& & & \\
& 566.7 & 0.339 & 3 \\
& 567.6 & 0.450 & 1 \\
$\mathrm{H}$ & 568.0 & 0.380 & 5 \\
& & & \\
& 656.3 & 0.6407 & 2 \\
\hline \hline
\end{tabular}

Table 3: Transitions used to measure atomic excitation temperature.

\begin{tabular}{lll}
$\begin{array}{ll}\text { Band Head } \\
\lambda(\mathrm{nm})\end{array}$ & $\mathrm{G}(\mathrm{eV})$ & $\mathrm{f}$ \\
\hline \hline & & \\
380.5 & 7.24 & 0.76 \\
375.5 & 11.52 & 0.52 \\
\hline \hline
\end{tabular}

Table 4: Bands used to measure $\mathrm{N}_{2}$ vibrational temperature. Both are $C^{3} \Pi_{u}-B^{3} \Pi_{g}$ transitions 


\begin{tabular}{llll}
\hline \hline $\begin{array}{l}\text { Axial position } \\
\text { from constrictor } \\
\text { (expansion ratio) }\end{array}$ & $\begin{array}{c}\text { atomic excitation } \\
\text { temperature }\end{array}$ & $\begin{array}{c}\text { molecular vibration } \\
\text { temperature }\end{array}$ & $\begin{array}{c}\text { molecular rotaion } \\
\text { temperature }\end{array}$ \\
\hline \hline $3 \mathrm{~mm}(13.9: 1)$ & $5.0-5.4 \mathrm{~s}$ & $5.1-5.6 \mathrm{~s}$ & $4.9-5.6 \mathrm{~s}$ \\
$6 \mathrm{~mm}(56.1: 1)$ & $6.9-7.6 \mathrm{~s}$ & $7.0-7.8 \mathrm{~s}$ & $7.1-7.7 \mathrm{~s}$ \\
$9 \mathrm{~mm}(126: 1)$ & $8.1-8.5 \mathrm{~s}$ & $8.2-9.7 \mathrm{~s}$ & $8.3-8.6 \mathrm{~s}$ \\
\hline
\end{tabular}

Table 5: Approximate time constants for plasma temperature

to reach $63 \%$ of the final values after thruster ignition

\begin{tabular}{|c|c|}
\hline timı: (s) & process \\
\hline 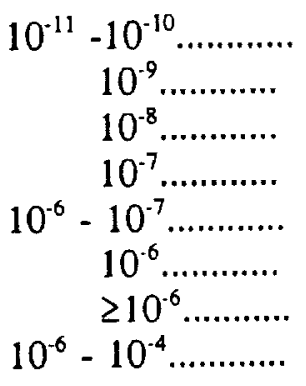 & $\begin{array}{l}\text { electron self relaxation, Ref. } 18 \\
\text { hydrogen-hydrogen (or proton) kinetic relaxation, Ref. } 18 \\
\text { electron - proton kinetic relaxation, Ref. } 18 \\
\text { direct electron - hydrogen relaxation, Ref. } 18 \\
\mathrm{~N}_{2} \text { rotational relaxation, Ref. } 17 \\
\text { hydrogen - } \mathrm{N}_{2} \text { kinetic relaxation, Ref. } 18 \\
\text { average particle residence time in the nozzle } \\
\mathrm{N}_{2} \text { vibrational relaxation, Ref. } 17\end{array}$ \\
\hline
\end{tabular}

Table 6: Relaxation times in the arcjet nozzle plasma 


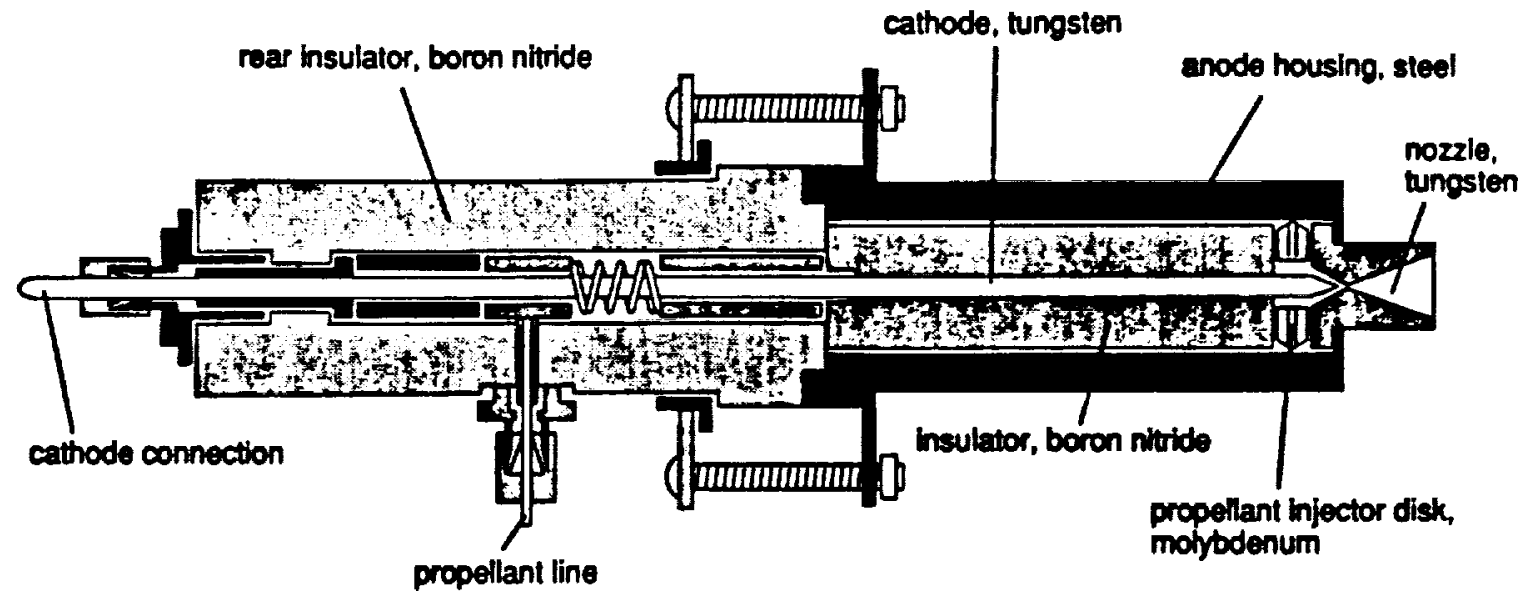

Figure 1. Schematic of arcjet used for spectroscopic measurements.

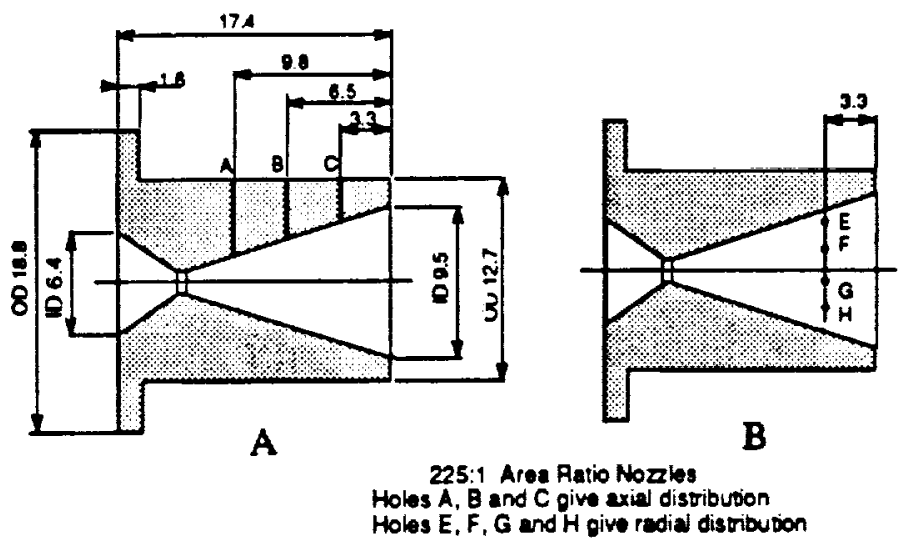

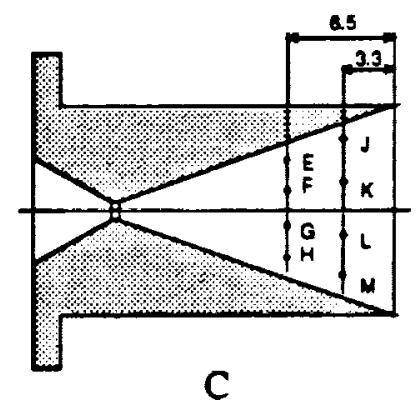

400:1 Area Ratio Nozzie Holes E,F,G,H\& J,K,L,M provide radial distributions at area raos of 126:1 and 225:1.

Figure 2. Schematics of three nozzles used in this study. Holes drilled in nozzle wall are all $0.25 \mathrm{~mm}$ in diameter. Not to scale. All dimensions in millimeters.

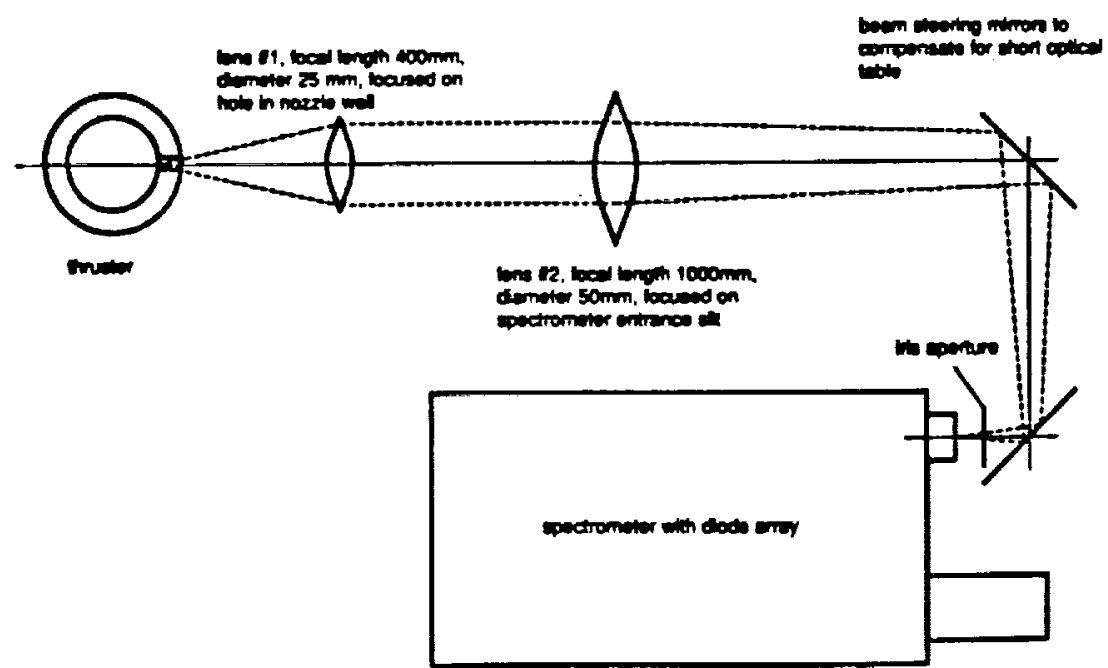

Figure 3. Optical arrangement used to image the holes in the arcjet nozzle walls onto the spectrometer entrance slit. 


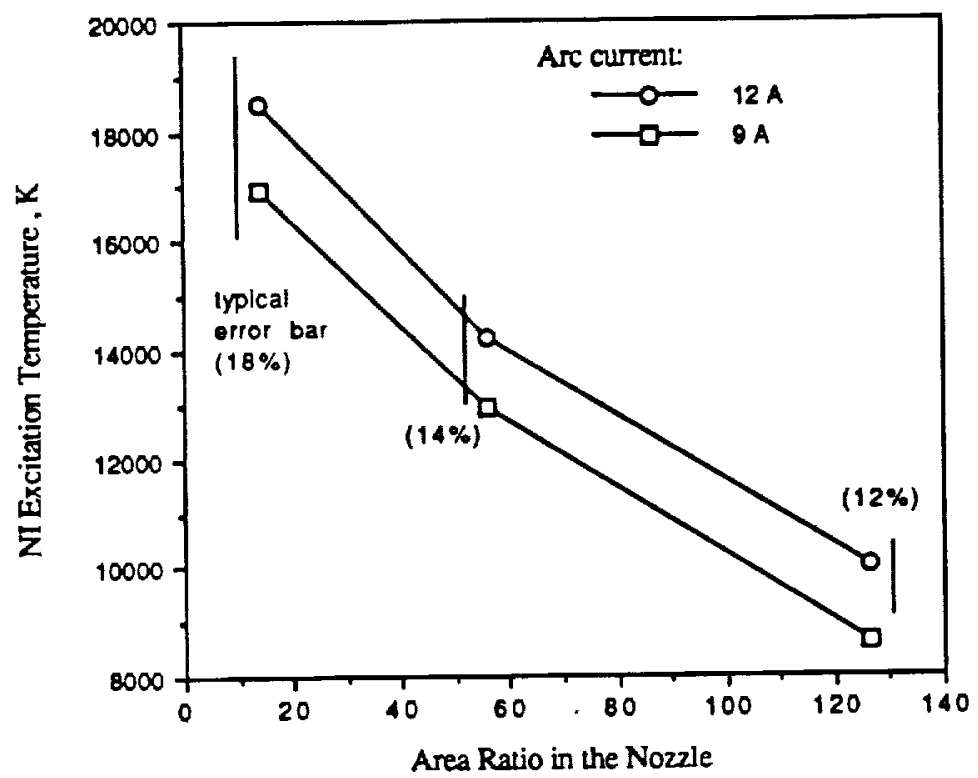

a. Neutral nitrogen.

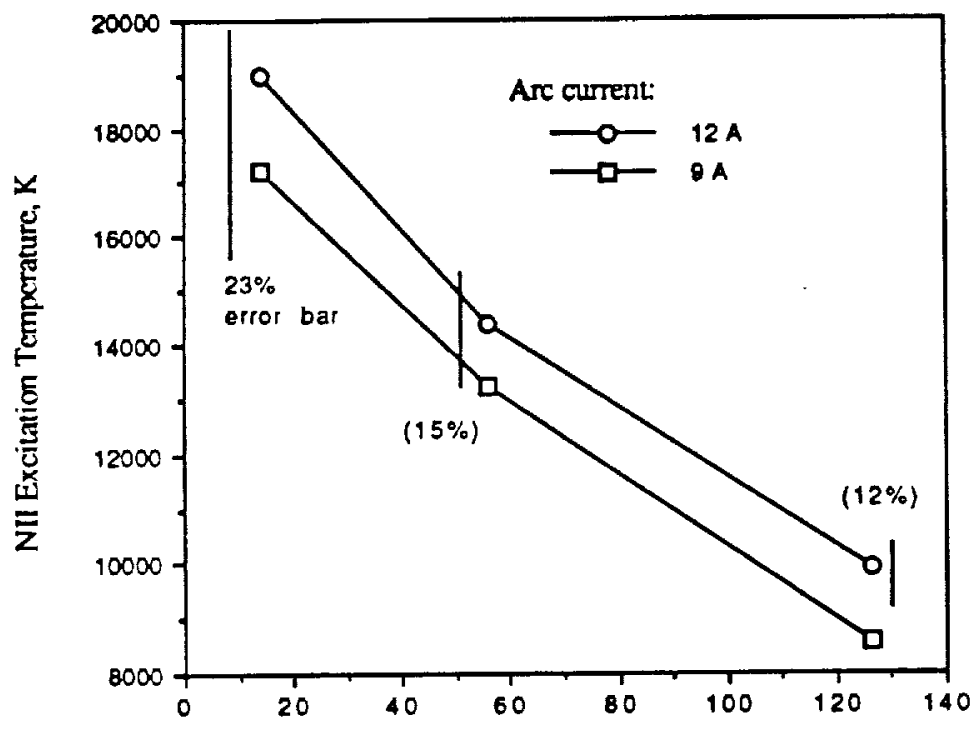

b. Singly ionized nitrogen.

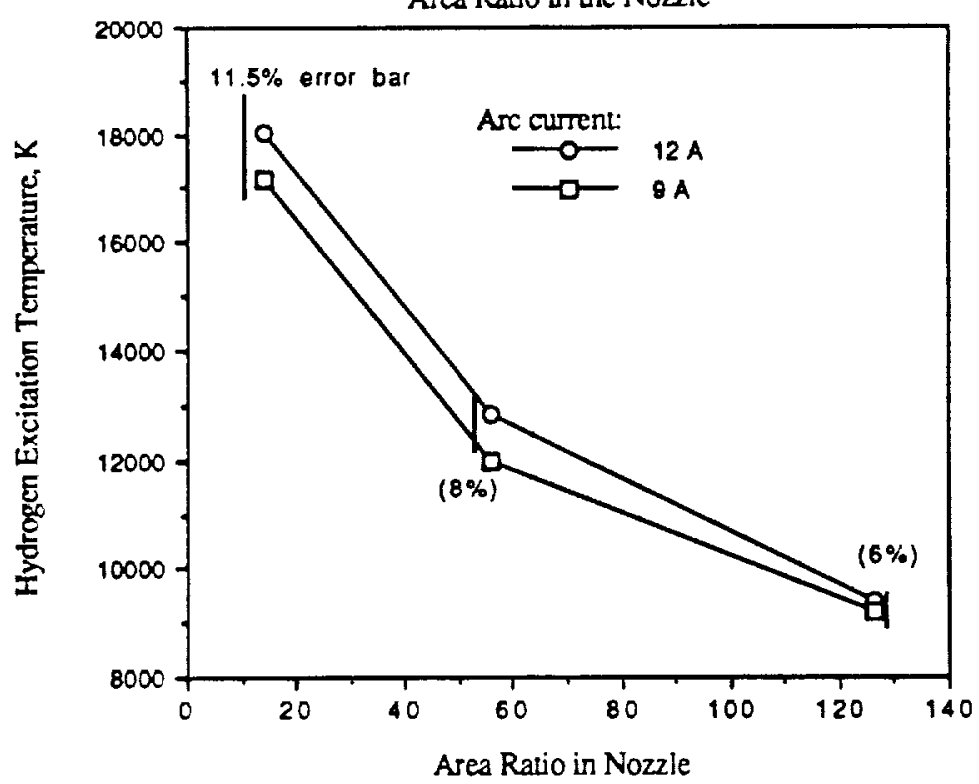

c. Neutral hydrogen.

Figure 4. Electron excitation temperature as a function of area ratio in the nozzle for three plasma species. 


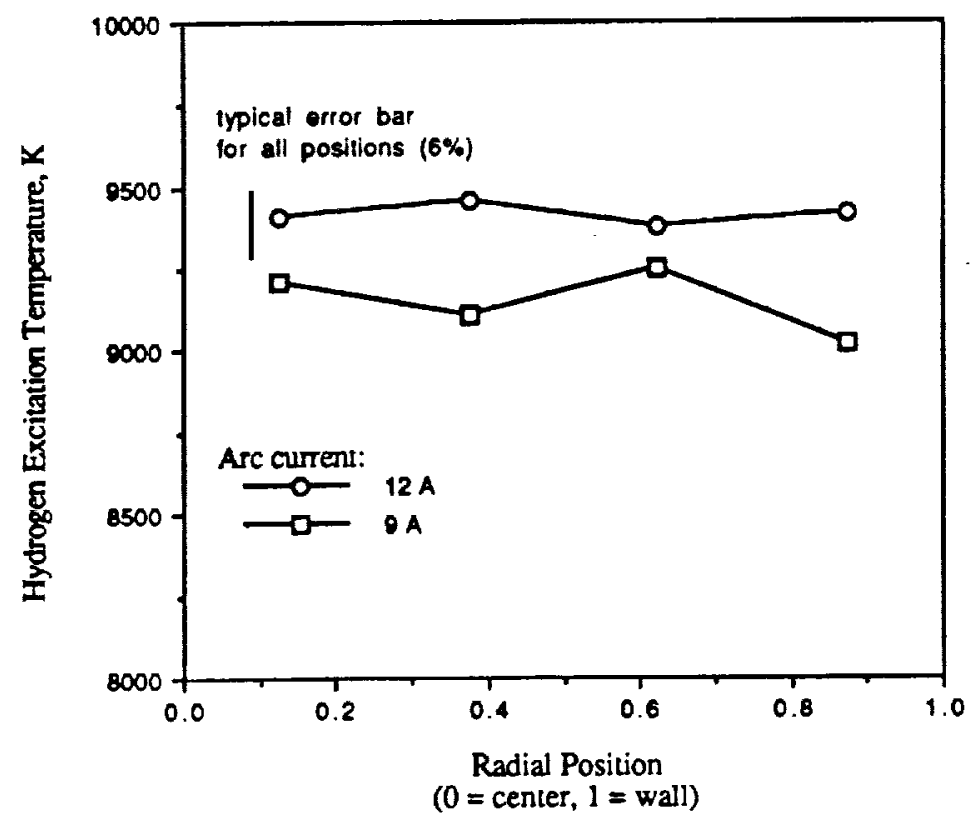

a. 225:1 nozzle at area ratio of $126: 1$.

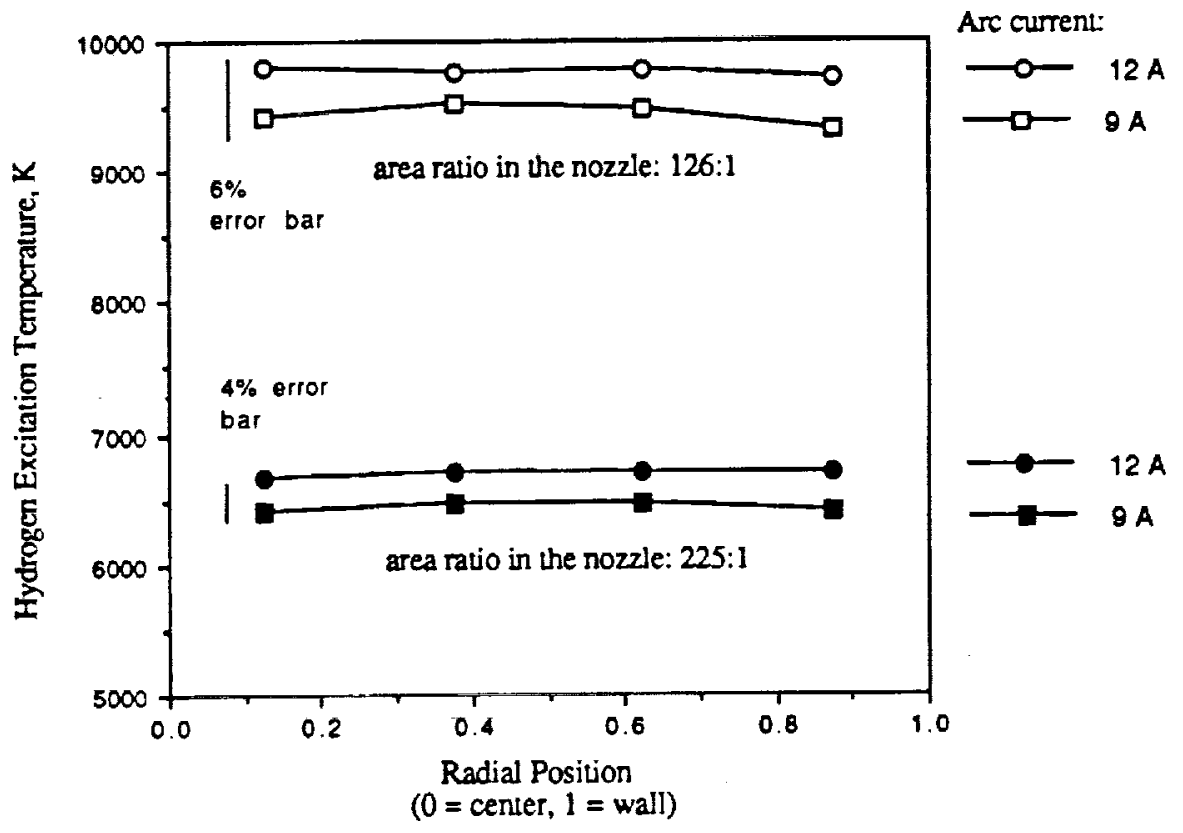

b. $400: 1$ nozzle at area ratios of $126: 1$ and $225: 1$.

Figure 5. Neutral hydrogen electron excitation temperature as a function of radial position in both the 225:1 and 400:1 nozzles. 


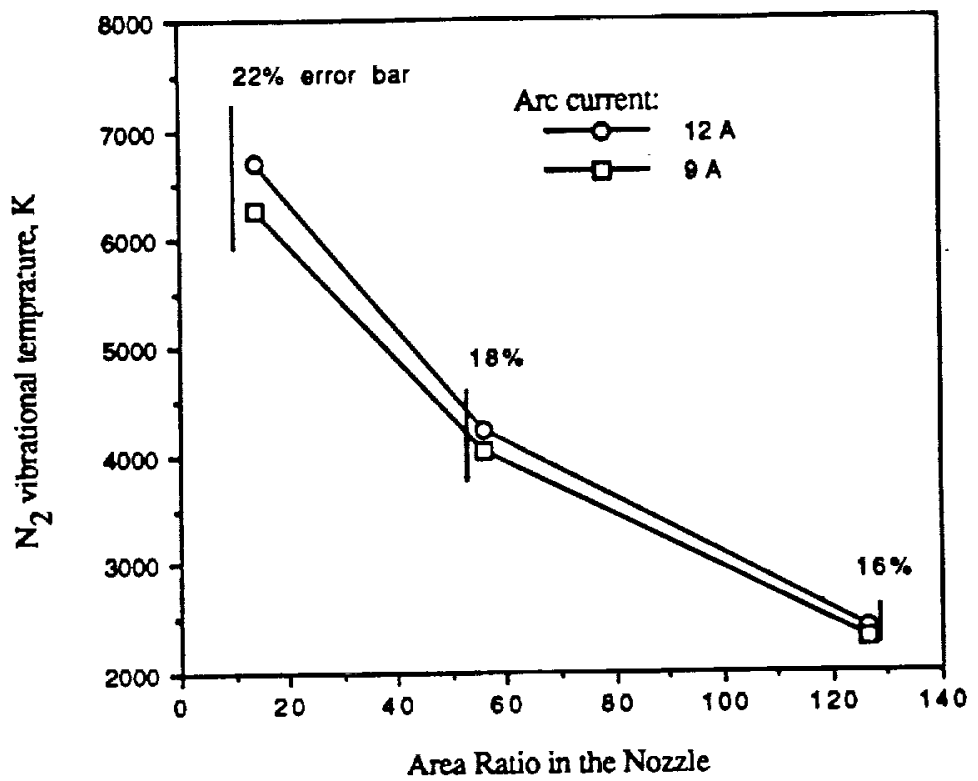

Figure 6. $\mathrm{N}_{2}$ vibrational temperature as a function of area ratio in the 225:1 nozzle.

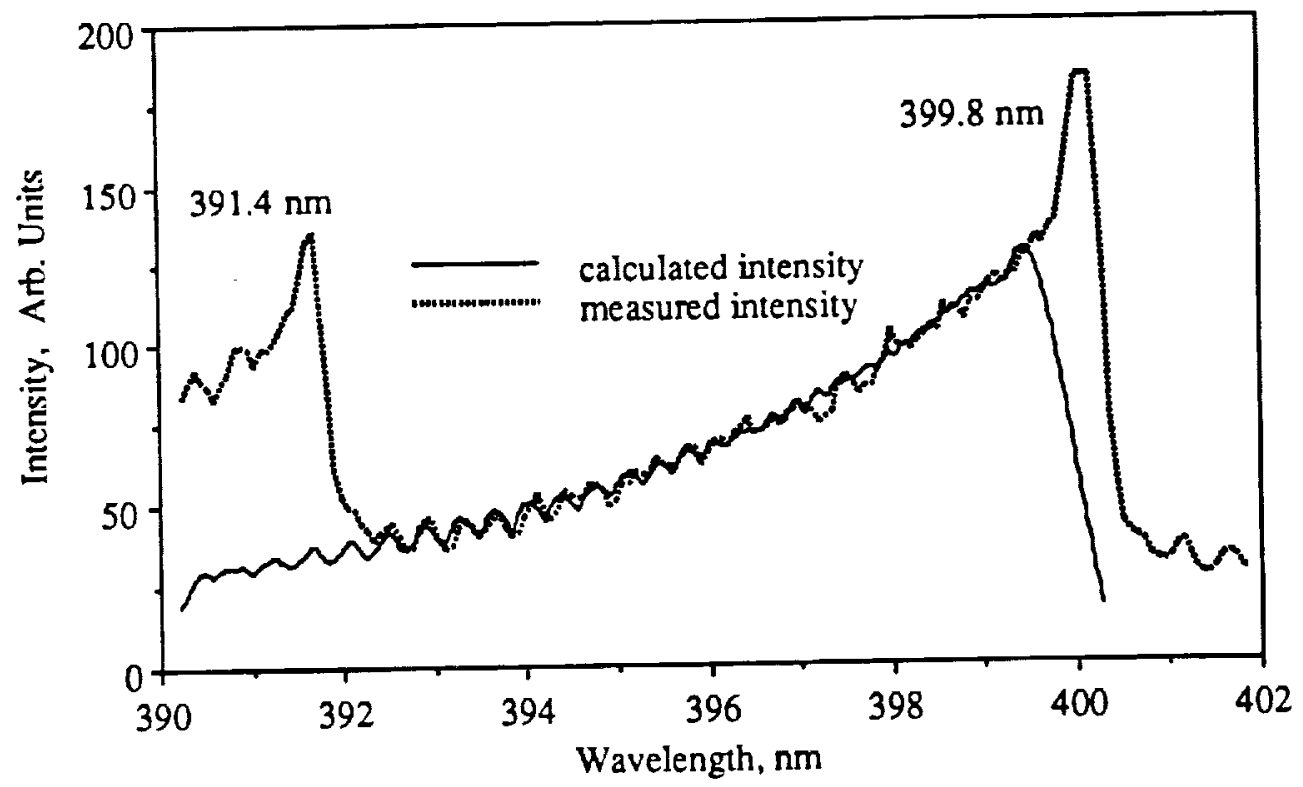

Figure 7. Typical experimental and calculated $\mathrm{N}_{2}$ rotational band intensity distributions. 


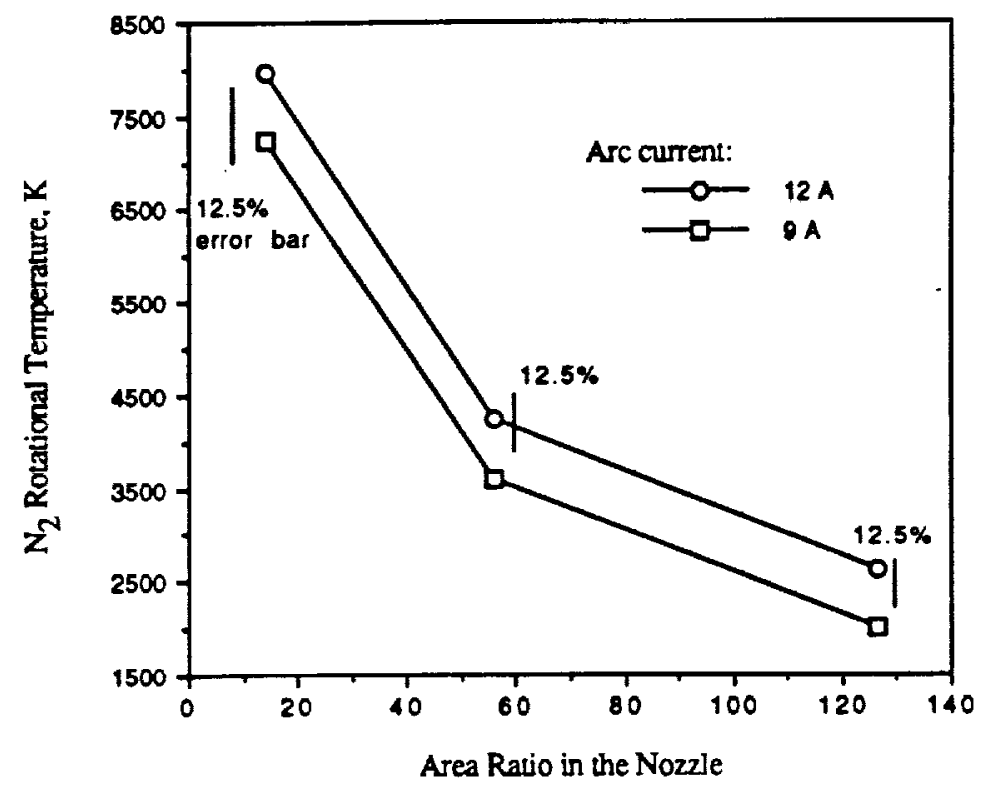

Figure 8. $\mathrm{N}_{2}$ rotational temperature as a function of area ratio in the 225:1 nozzle.

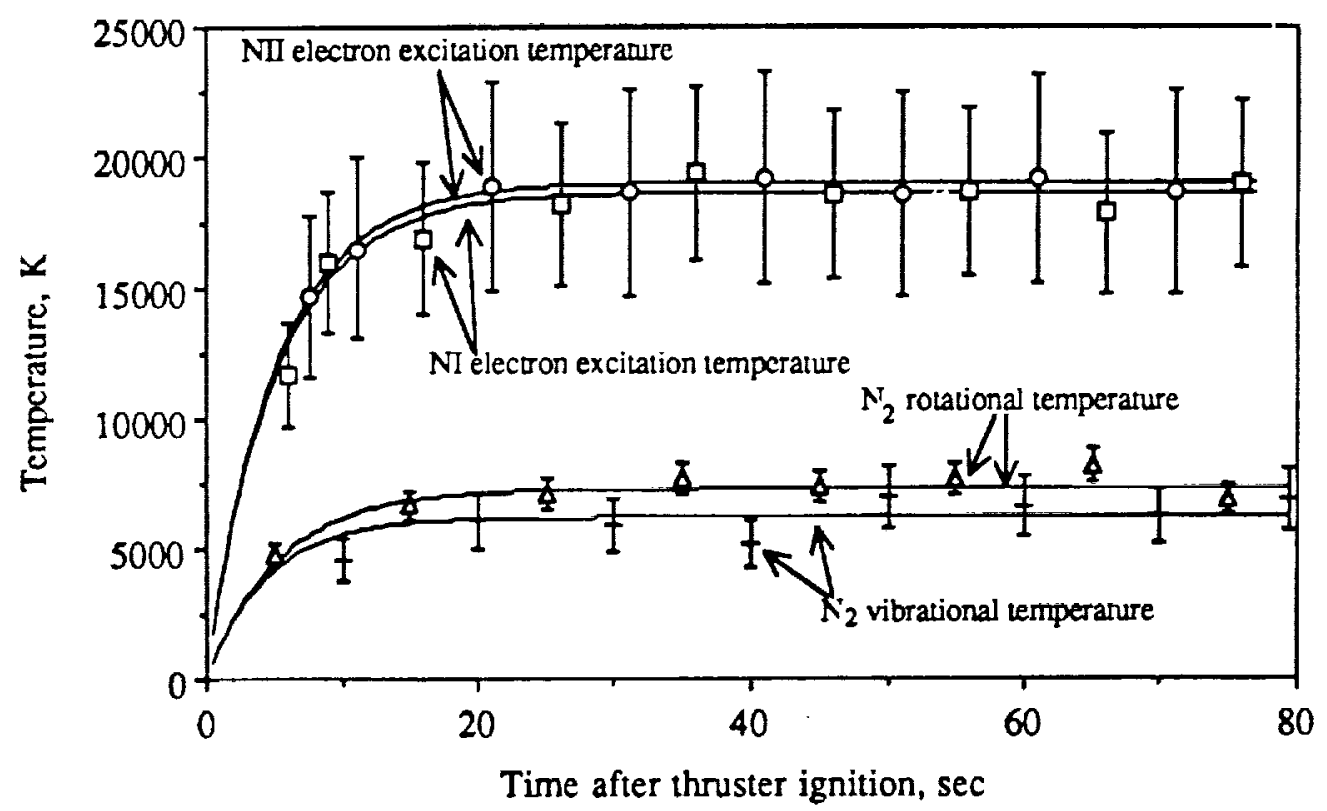

Figure 9. Time evolution of the plasma temperatures during arcjet start-up. 


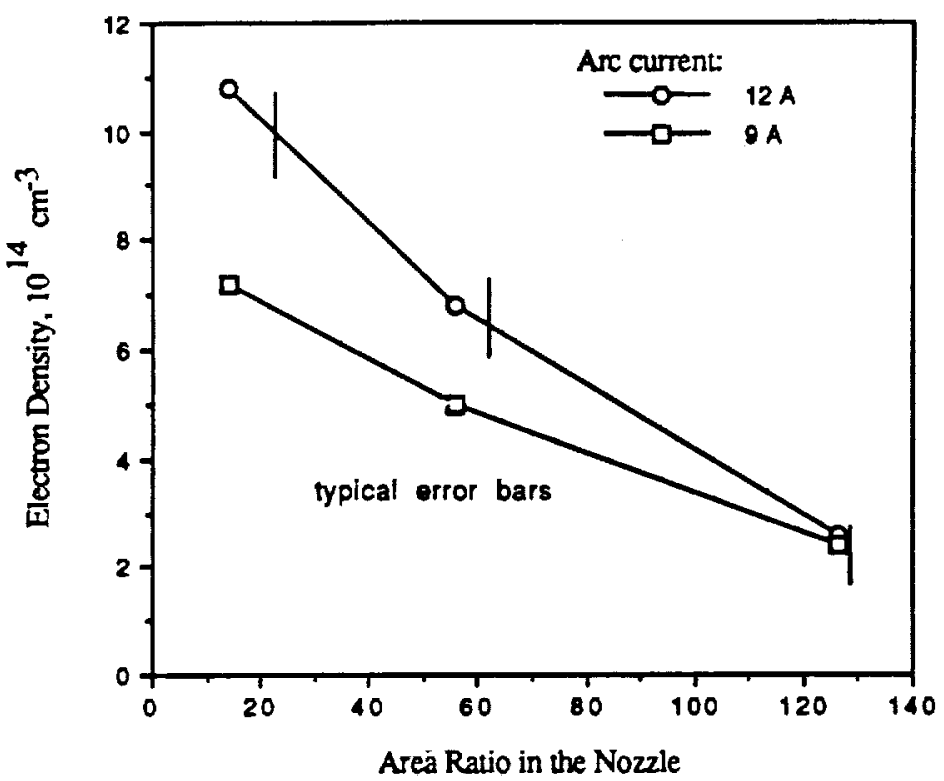

Figure 10. Electron density as a function of area ratio in the 225:1 nozzle.

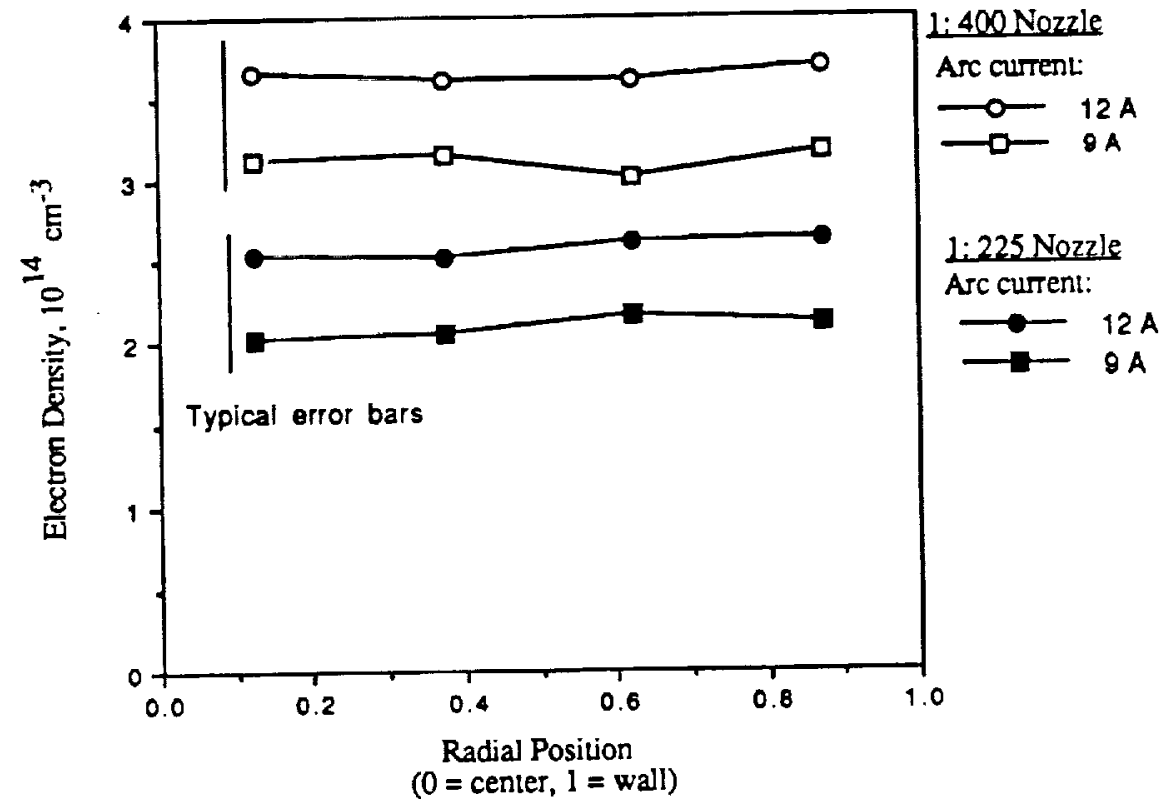

Figure 11. Electron density as a function of radial position for both the 225:1 and 400:1 nozzles at an area ratio of 126:1. 


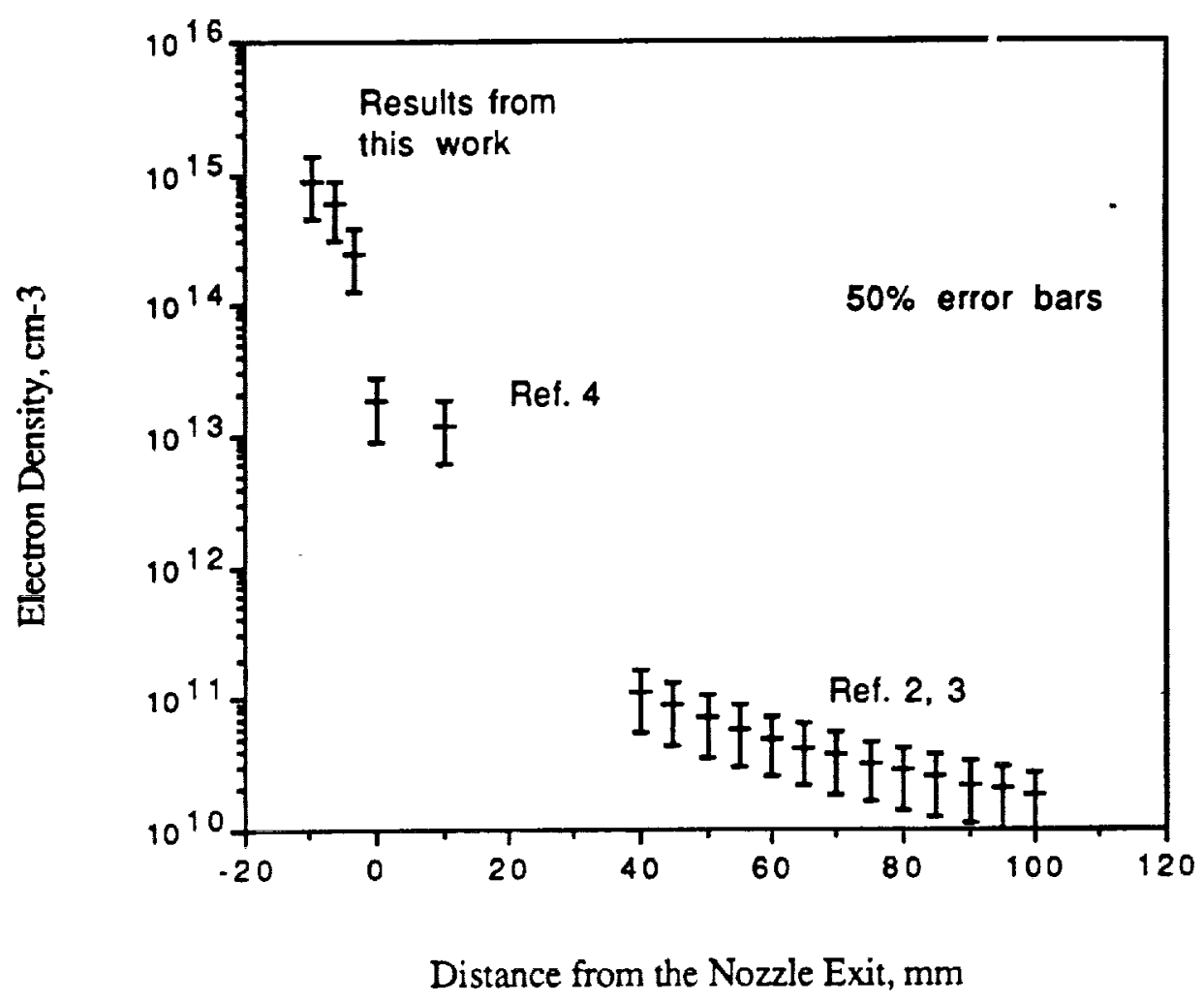

Figure 12. Comparison of electron density measurements in the arcjet plume with results from this work. 


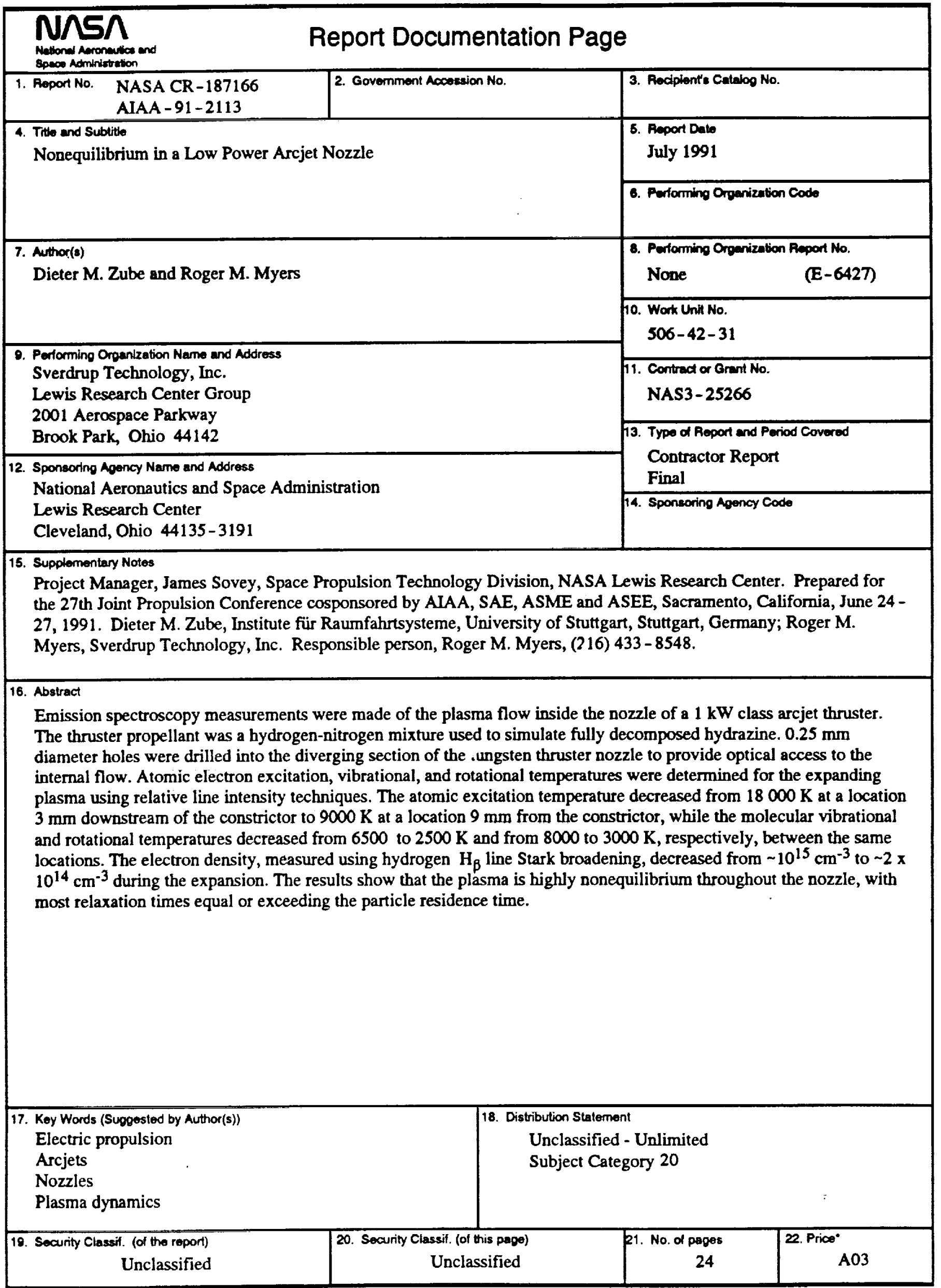

